Article

\title{
In-Syringe Micro Solid-Phase Extraction Method for the Separation and Preconcentration of Parabens in Environmental Water Samples
}

\author{
Geaneth Pertunia Mashile, Anele Mpupa and Philiswa Nosizo Nomngongo * (D) \\ Department of Applied Chemistry, University of Johannesburg, Doornfontein Campus, P.O. Box 17011, \\ Johannesburg 2028, South Africa; petmashile2009@hotmail.com (G.P.M.); anelempupa@yahoo.com (A.M.) \\ * Correspondence: pnnomngongo@uj.ac.za or nomngongo@yahoo.com; Tel.: +27-11-559-6187
}

Academic Editor: Victoria F. Samanidou

Received: 22 May 2018; Accepted: 13 June 2018; Published: 14 June 2018

\begin{abstract}
In this study, a simple, rapid and effective in-syringe micro-solid phase extraction (MSPE) method was developed for the separation and preconcetration of parabens (methyl, ethyl, propyl and butyl paraben) in environmental water samples. The parabens were determined and quantified using high performance liquid chromatography and a photo diode array detector (HPLC-PDA). Chitosan-coated activated carbon (CAC) was used as the sorbent in the in-syringe MSPE device. A response surface methodology based on central composite design was used for the optimization of factors (eluent solvent type, eluent volume, number of elution cycles, sample volume, sample $\mathrm{pH})$ affecting the extraction efficiency of the preconcentration procedure. The adsorbent used displayed excellent absorption performance and the adsorption capacity ranged from $227-256 \mathrm{mg} \mathrm{g}^{-1}$. Under the optimal conditions the dynamic linear ranges for the parabens were between 0.04 and $380 \mu \mathrm{g} \mathrm{L}^{-1}$. The limits of detection and quantification ranged from 6-15 $\mathrm{ng} \mathrm{L}^{-1}$ and $20-50 \mathrm{ng} \mathrm{L}^{-1}$, respectively. The intraday (repeatability) and interday (reproducibility) precisions expressed as relative standard deviations (\%RSD) were below 5\%. Furthermore, the in-syringe MSPE/HPLC procedure was validated using spiked wastewater and tap water samples and the recoveries ranged between from 96.7 to $107 \%$. In conclusion, CAC based in-syringe MSPE method demonstrated great potential for preconcentration of parabens in complex environmental water.
\end{abstract}

Keywords: in-syringe micro solid-phase extraction; personal care products; response surface methodology; parabens; wastewater

\section{Introduction}

Over the years living standards have improved and so has the production and use of cosmetics. Cosmetics are defined as any substance or mixture intended for use on the external parts of the human body, teeth and mucous membrane as defined by the European Union 1223/2009 (Article 2,1.Aa) [1]. This mainly includes personal care products (lotions, soup, perfume, deodorant), beauty products (nail polish, mascara, lip stick, etc.), hair care products (shampoo, hair dyes and gel, among others), oral products (mouthwash, toothpaste) [2]. The compounds or chemical substances within the cosmetics are connected to their intended use, that is, antioxidants, preservatives, fragrances, pigment, antimicrobial and UV-filters [3]. One of the most commonly used compounds in cosmetics, pharmaceuticals and personal care products (PPCPs) are parabens. These compounds are used primarily for their antimicrobial and antibacterial properties [4]. In cosmetics and personal care products the most used parabens are methyl, ethyl, propyl as well as butyl paraben which are often times used in combination with other preservatives [5]. They are preferred over other alternatives due to their low cost, broad spectrum of activity, thermal stability and applicability over a wide $\mathrm{pH}$ range [6]. 
Traditionally, parabens have been considered as low toxicity compounds, however more recent studies have found that certain parabens exhibit endocrine disrupting effects, which in turn can lead to a potential increase in breast cancer incidence [7] or the development of malignant melanomas [8], amongst other effects. This is compounded by the ability of parabens to be absorbed into the human skin due to dermal exposure to products which contain these compounds [4]. Moreover, parabens contain phenolic hydroxyl groups, which are capable of producing chlorinated degradation by-products when in contact with chlorinated water as in tap and swimming pool water [9]. The chlorinated by-products which originate from personal care products are said to be more toxic to aquatic organisms that their corresponding parent compounds [10]. The wide use of products containing such compounds has contributed to the direct introduction of parabens into the aquatic environment via the domestic and industrial wastewater route [11]. As a result this has prompted the development of various analytical methods for the determination of parabens in environmental samples (such as water, sewage influents and effluents) [12], soil [13,14], among others.

Over the years various analytical techniques for the determination of parabens in different matrices have been developed, including gas-chromatography (GC) $[9,15,16]$, high performance liquid chromatography (HPLC) [13,17], capillary zone electrophoresis (CZE) [4] and ultra performance liquid chromatography $[18,19]$ amongst others. HPLC methods are the most widely used for the analysis and determination of parabens since techniques such as GC require prior derivatization of the compounds [20].

These analytical techniques are often combined with pretreatment procedures to eliminate non-polar matrix components and also improve the selectivity, reliability and accuracy of the analysis [21,22]. As a result, various extraction and preconcentration techniques have to be used for analysis of parabens such as magnetic solid phase extraction (MSPE) [23], solid phase extraction (SPE) [19]; dispersive liquid liquid microextraction (DLLME) [24], stir-bar sorptive extraction (SBSE) [25] and solid phase microextraction (SPME) [26], amongst others.

Some conventional pretreatment procedures like LLE are scarcely used in the determination of parabens due to their tediousness and high consumption of solvents, so even when automated, the column length limits the ability to separate the different parabens [27]. Thus, conventional SPE has been used as a better alternative to solve these issues, which has resulted in an increase in the application of SPE for the determination of parabens [28]. SPE provides advantages such as preconcentration of trace analytes from larger sample volumes, reduction and elimination of matrix interferences, as well as less possibility of cross-contamination, simplicity, effectiveness of extraction, sensibility and high selectivity $[20,22]$. Moreover it can easily be automated with a wide variety of available sorbents which have been developed over the years [28]. However, SPE also presents some drawbacks such as limitations in treatment of large sample volumes, its time consuming nature, need for pre-treatment of sorbents prior to extraction, obstruction and clogging of cartridges and relatively low extraction efficiencies. In addition, aggregation [29] of particles may occur reducing the active surface area [30]. SPE cartridges used are usually made from plastics, which can absorb the analytes and hence increase the interference in the analysis [31]. Therefore, to eliminate the drawbacks of conventional SPE, sample pretreatment methods like solid phase microextraction (SMPE) were developed [32]. SPME was proposed as the better alternative as it allows the combination of sampling and sample extraction in a single step, which also eliminates the use of organic solvents for analysis of parabens. It is also a technique that is effective due to its advantages of high enrichment factor, sample operation and solvent-free microextraction [33].

Therefore, the aim of this work was to develop a quick, low solvent consumption, simple and easy to use analytical method based on in-syringe micro-solid phase extraction (MSPE) for the simultaneous preconcentration and determination of four common parabens in environmental matrices. A chitosan-coated activated carbon (CAC) composite was applied as a sorbent in SPME for the preconcentration of parabens in environmental water samples. Activated carbon was chosen due to its high adsorption capacity and affinity for organic compounds/pollutants [34]. This combination improves the performance and serves as a proper support for chitosan as an adsorbent by improving 
its mechanical and chemical properties. Moreover an added advantage is the lesser quantity of chitosan needed to create a new adsorbent without disrupting the adsorption capacity of the formed adsorbent significantly [35]. To the best of our knowledge, there are limited or no reports on the simultaneous extraction of parabens using a chitosan-coated activated carbon-based in-syringe MSPE method. The efficiency of the preconcentration method for extraction of parabens is due to the unique properties of the adsorbent. A response surface methodology (RSM)-based central composite design (CCD) was used to determine the optimum experimental conditions.

\section{Results and Discussion}

\subsection{Characterization of Chitosan-Coated Activated Carbon (CAC)}

The BET surface area of chitosan-coated activated carbon (CAC) is higher than that of activated carbon. An improvement on the properties of activated carbon was possible thanks to the presence of chitosan acting as a support for coating AC. A result of coating the chitosan is an increase in the surface area of the activated carbon while the pore volume and pore size are decreased due to the fact the chitosan can block the pores on the activated carbon, as seen in Table 1.

Table 1. Characteristics of adsorbent.

\begin{tabular}{ccc}
\hline Parameter & Activated Carbon & Chitosan Coated Activated Carbon \\
\hline BET surface area $\left(\mathrm{m}^{2} / \mathrm{g}\right)$ & 1075.45 & 1181 \\
Pore Volume $\left(\mathrm{cm}^{3} / \mathrm{g}\right)$ & 0.7553 & 0.733 \\
Pore size $(\mathrm{nm})$ & 4.839 & 4.545 \\
\hline
\end{tabular}

\subsection{Optimization of in-Syringe SPME}

The optimization of factors affecting the experimental preconcentration procedure was carried out by means of an experimental design approach, whereby the effects of important variables such as mass of adsorbent, sample $\mathrm{pH}$ and eluent volume were determined using response surface methodology (RSM) based on a central composite design (CCD). The analysis of variance (ANOVA) represented in terms of Pareto chart was used to explore the significance of the effects on the in-syringe MSPE procedure (Figure 1).

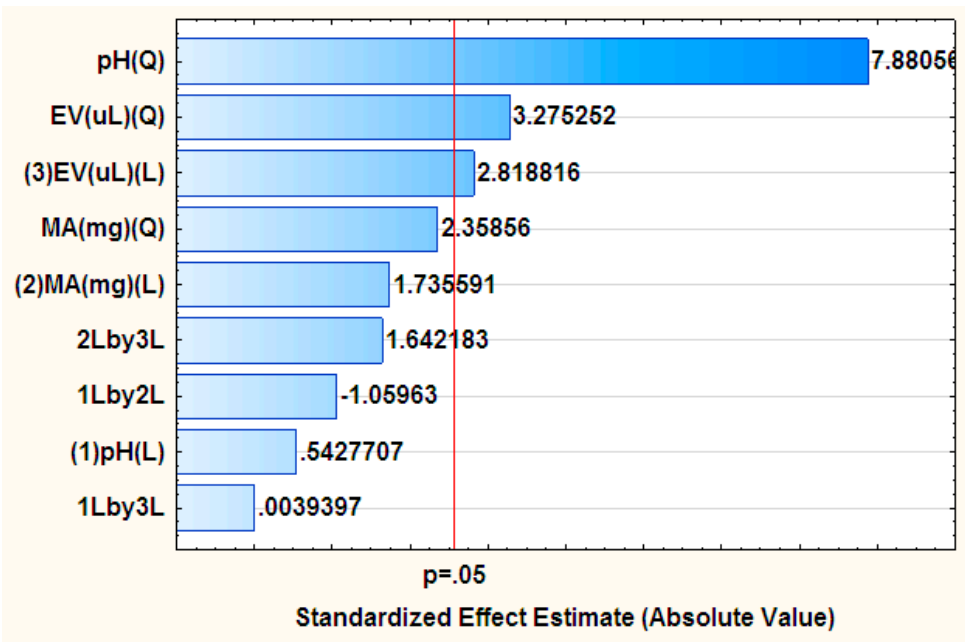

Figure 1. Pareto chart of standardized effects for variables in the preconcentration for parabens: The " $Q$ " and " $\mathrm{L}$ " in brackets indicate whether the effects are quadratic or linear, respectively. The "2Lby3L" indicates the linear interactions between MA and EV, the "1Lby2L" referrers to the interactions between $\mathrm{pH}$ and MA and "1Lby3L" is for the the $\mathrm{pH}$ and $\mathrm{EV}$ interactions. 
According to Figure 1 the effect of $\mathrm{pH}$ and mass of adsorbent were insignificant at the 95\% confidence level, contrary to the eluent volume used for the preconcentration of parabens. The sample $\mathrm{pH}$ and all interactions were not significance at a 95\% confidence level for the preconcentration of parabens. RSM was used to establish an extrapolative model which denotes changes in the response, depending on the contributing factors. The quadratic equation for the model illustrated the dependence of the analytical response (\%recovery) with respect to the evaluated variables [36].

The 3D response surface plots showing the analytical response against individual factors are shown in Figure 2, which illustrates the interaction of the $\mathrm{pH}$ with the mass of adsorbent and eluent volume as well as the interaction of eluent volume with mass of adsorbent, respectively. As seen an enhanced analytical response (\%recovery) at $\mathrm{pH}$ values between 5 and 8 was observed. This demonstrated that the extraction and pre-concentration of parabens depended on the sample $\mathrm{pH}$. In addition, it was observed that maximum recoveries were achieved at eluent volumes above $500 \mu \mathrm{L}$. This is because volumes below $500 \mu \mathrm{L}$ were not enough to elute all the analytes from the adsorbent. The percentage recovery dependency as a function of the interaction between mass of adsorbent and $\mathrm{pH}$ revealed that the analytical response increased with increasing mass of adsorbent. This was probably due to the high surface area and small particle size of the chitosan-coated activated carbon.
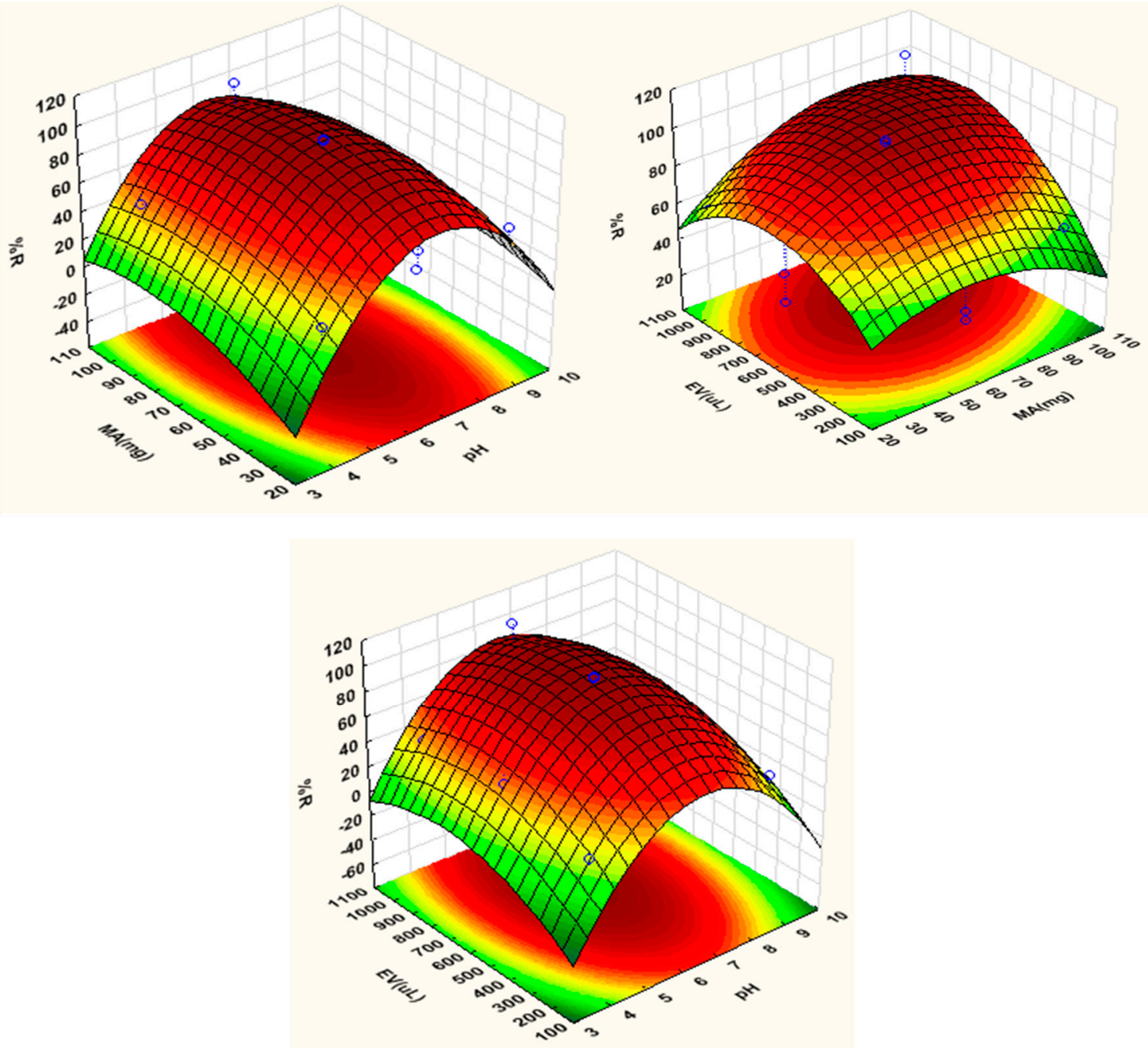

Figure 2. Response surface obtained for parabens after extraction and preconcentration by in-syringe MSPE. 
In addition to the 3D response surface plots, the estimation of the optimum conditions was further carried out using the profile for predicted values and desirability. As seen in Figure 3 the desirability of 1.0 was assigned for maximum recoveries (105\%), 0.0 for minimum $(26.5 \%)$ and 0.5 for middle $(65.8 \%)$. Figure 3 also shows the individual desirability scores for preconcentration of parabens (left hand side (bottom) and the, the desirability value of 1.0 was chosen as the target value to be used to obtain optimum conditions and the percent recovery obtained from plots for each parameter in the model is shown at the top left hand side. According to Khodadoust et al. [37], the figures on the top left hand side illustrate the changes in the level of each individual factor and its analytical response as well as its overall desirability. Therefore, based on the calculations from the 3D plots and desirability score of 1.0, the percentage recovery of parameters was optimized at 101.5 and the optimum conditions were mass of adsorbent $81 \mathrm{mg}$, eluent volume 800 and sample pH 6.5.

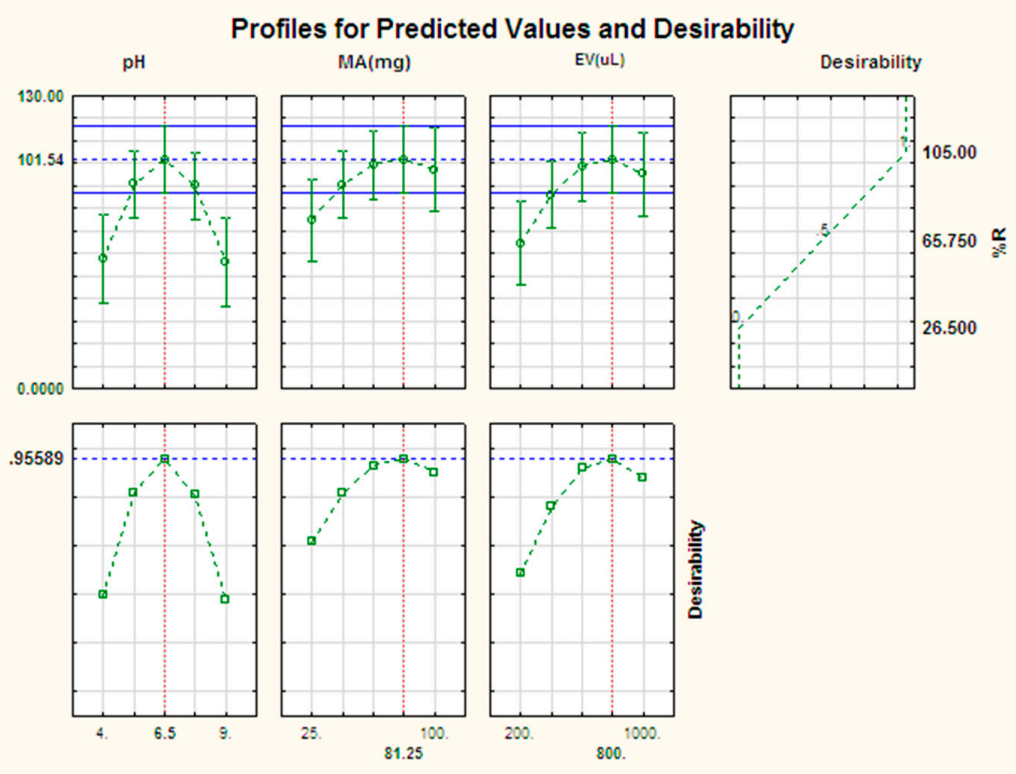

Figure 3. Profiles for predicated values and desirability function for pre-concentration of parabens.

\subsection{Adsorption Capacity of CAC}

Under optimum conditions, the adsorption capacities of the CAC toward the parabens were investigated. To evaluate the adsorption capacity, $100 \mathrm{mg} \mathrm{L}^{-1}$ of paraben mixture solution was sonicated for $100 \mathrm{~min}$ at room temperature and the concentration at equilibrium were determined using HPLC-PDA. The adsorption capacities for each analyte are presented in Table 2.

Table 2. Adsorption capacity (mg/g) of chitosan coated activated carbon.

\begin{tabular}{cc}
\hline Paraben & Adsoption Capacity (mg/g) \\
\hline Methyl & 227 \\
Ethyl & 236 \\
Propyl & 256 \\
Butyl & 241 \\
\hline
\end{tabular}

\section{Analytical Figures of Merit}

Under optimal conditions the analytical performance of the proposed method was investigated in terms of precision (intra- and interday), linearity, limits of detection (LOD) and limits of quantification (LOQ) (Table 3). Seven point (triplicate) calibration curves for the parabens were constructed by plotting the peak area of the signal acquired using HPLC/PDA as a function of concentrations of parabens. 
Table 3. Analytical figures of merit of the proposed in-syringe MSPE/HPLC method for the preconcentration and determination of parabens.

\begin{tabular}{|c|c|c|c|c|c|c|}
\hline \multirow{2}{*}{ Paraben } & \multirow{2}{*}{ Linearity $\left(\mu \mathrm{g} \mathrm{L}^{-1}\right)$} & \multirow{2}{*}{ Correlation Coefficient $\left(R^{2}\right)$} & \multirow{2}{*}{$\operatorname{LOD}\left(\operatorname{ng~L~L~}^{-1}\right)$} & \multirow{2}{*}{$\operatorname{LOQ}\left(\mu \mathrm{g} \mathrm{L}^{-1}\right)$} & \multicolumn{2}{|c|}{ Precision (\%RSD) } \\
\hline & & & & & Intraday & Interday \\
\hline Methyl & $0.05-375$ & 0.9991 & 12 & 40 & 2.1 & 3.3 \\
\hline Ethyl & $0.04-350$ & 0.9989 & 10 & 33 & 1.8 & 2.5 \\
\hline Propyl & $0.04-380$ & 0.9995 & 6 & 20 & 1.6 & 3.9 \\
\hline Butyl & $0.06-380$ & 0.9992 & 15 & 50 & 1.5 & 2.0 \\
\hline
\end{tabular}

Table 4. Trueness experiment using three level concentrations of each analyte.

\begin{tabular}{|c|c|c|c|c|c|}
\hline Paraben & Added Value $\left(\operatorname{ng~L}^{-1}\right), n=5$ & Measured Value $\left(\mathrm{ng} \mathrm{L}^{-1}\right), n=5$ & $\%$ RSD & \multicolumn{2}{|c|}{ Trueness } \\
\hline \multirow{2}{*}{ Methyl } & 10 & $9.87 \pm 0.17$ & 1.7 & 98.7 & -1.3 \\
\hline & 50 & $49.8 \pm 1.8$ & 3.6 & 99.6 & -0.4 \\
\hline \multirow[b]{2}{*}{ Ethyl } & 10 & $9.92 \pm 0.23$ & 2.3 & 99.2 & -0.8 \\
\hline & 30 & $29.8 \pm 0.5$ & 1.7 & 99.3 & -0.7 \\
\hline \multirow[t]{3}{*}{ Propyl } & 30 & $29.2 \pm 0.6$ & 2.1 & 97.3 & -2.7 \\
\hline & 50 & $50.3 \pm 1.3$ & 2.6 & 101 & 0.6 \\
\hline & 10 & $9.76 \pm 0.16$ & 1.6 & 97.6 & -2.4 \\
\hline \multirow[t]{2}{*}{ Butyl } & 30 & $29.7 \pm 0.9$ & 3.0 & 99.0 & -1.0 \\
\hline & 50 & $50.1 \pm 1.2$ & 2.4 & 100 & 0.2 \\
\hline
\end{tabular}


Calibration curve linearity was observed in the range of $0.05-375 \mu \mathrm{g} \mathrm{L} \mathrm{L}^{-1}$ for methylP, 0.04-350 $\mu \mathrm{g} \mathrm{L}^{-1}$ for ethylP, $0.04-380 \mu \mathrm{g} \mathrm{L}^{-1}$ for propylP and butylP $0.06-380 \mu \mathrm{g} \mathrm{L}{ }^{-1}$. The correlation coefficient $\left(R^{2}\right)$ ranged from 0.9989 to 0.9995 (Table 4). The LODs, LOQs, enrichment factor and pre-concentration factor ranged 6-15 $\mathrm{ng} \mathrm{L}^{-1}, 20-50 \mathrm{ng} \mathrm{L}^{-1}, 100$ and $150-175$, respectively.

The intraday precision (repeatability) was evaluated by analyzing fifteen successive replicates $50 \mu \mathrm{g} \mathrm{L}^{-1}$. The precision expressed in the form of relative standard deviation (\%RSD) ranged from 1.5 to $2.1 \%$. In addition, the interday precision (reproducibility of in-syringe device, triplicates, five working days) were between $2.0 \%$ and $3.9 \%$.

Due to the absence of certified reference materials (CRM) for parabens in water samples, spike recovery experiments were performed for assessing the trueness of the developed method. The trueness validation procedure was carried out by spiking tap water at three concentration levels, that is low (10 ng L $\left.{ }^{-1}\right)$, middle ( $\left.30 \mathrm{ng} \mathrm{L}^{-1}\right)$, and high $\left(50 \mathrm{ng} \mathrm{L}^{-1}\right)$. Samples were analyzed in triplicate over a period of five days and the trueness of the method was assessed using relative bias and recovery (Table 4). As seen from Table 4, the relative bias varied between $-2.7 \%$ and $1.7 \%$ while the recoveries were greater than $95 \%$ for all the studied analytes. In addition, the inter-day precision was less than $5 \%$ and these demonstrated the trueness of the developed method.

The analytical performance of the proposed in-syringe MSPE method for preconcentration and determination of parabens was compared with other different analytical procedures reported in the literature (Table 5). Thus, it can be observed that the proposed method has better analytical figures of merit compared to those reported by [19,38-44]. In addition, the analytical performances were comparable to those reported by [41] and lower than those reported by [42]. The results obtained in this work show that the in-syringe SPME-HPLC-DAD is efficient and a simple technique. Its optimum performances can be attributed to the attractive properties of the adsorbent. Thus, the method proved to have higher adsorption capacity, simple, cost effective and sensitive and efficient for the preconcentration and determination of parabens in water samples. 
Table 5. Comparison of the proposed microextraction method with literature for determination of parabans.

\begin{tabular}{|c|c|c|c|c|}
\hline Parabens & Matrices & Analytical Method & $\operatorname{LOD}\left(\operatorname{ng~L~}^{-1}\right)$ & References \\
\hline Methyl, ethyl, propyl, isopropyl, butyl, isobutyl, benzyl & Wastewater, River water & SPE/HPLC-CL & $0.08-0.44$ & [42] \\
\hline Methyl, ethyl, propyl & Cosmetics, beverages, water & HPLC-UV/ SUPRAS & $70-500$ & [43] \\
\hline Methyl, propyl, butyl, benzyl and benzophenone- 4 & Wastewater (Influent and effluent) & SPE-HPLC-MS/MS & $0.8-4.8$ & \\
\hline Methyl, ethyl, propyl, isopropyl, butyl, benzyl & Wastewater & SPE/UPLC-MS/MS & $221-21,423$ & [19] \\
\hline Methyl, ethyl, propyl, butyl & $\begin{array}{l}\text { Wastewater, river water, swimming } \\
\text { pool water }\end{array}$ & DLLME/GC-MS/MS & $3.90-27.5$ & {$[40]$} \\
\hline Methyl, ethyl, propyl & $\begin{array}{l}\text { Toothpaste, mouth rinse, shampoo, } \\
\text { tap water, river water }\end{array}$ & DLLME/HPLC-UV & $5-20$ & {$[41]$} \\
\hline Methyl, propyl & Underground water & HF-MMLLE/HPLC-DAD & $500-4600$ & [39] \\
\hline Ethyl, propyl, isobutyl, butyl & Lake and river water & HPLC-UV/DF- $\mu$ LPME & $1600-3500$ & [38] \\
\hline Methyl, ethyl, propyl, butyl & Wastewater, tap water & In-syringe MSPE/HPLC-PDA & $6-15$ & This work \\
\hline
\end{tabular}

Extraction methods: SPE: solid phase extraction, SBSE: stir-bar sorptive extraction, SPME: solid phase micro-extraction, DLLE; dispersive liquid-liquid extraction, MSPD: matrix solid-phase dispersion, DF- $\mu$ LPME: double-flow microfluidic based liquid phase micro-extraction, HF-MMLLE: hollow fiber-microporous membrane liquid-liquid extraction. Analytical methods: HPLC-CL: high performance liquid chromatography-chemiluminescence, UPLC: ultra-performance liquid chromatography-mass spectrometry, GC-MS: gas chromatography-mass spectrometry. 


\subsection{Analysis of Real Samples}

The proposed method was also used in the preconcentration and determination of parabens in three kinds of real water samples (influent, effluent and tap water) that were analysed by HPLC-DAD after the in-syringe-SPME procedure. Under optimized conditions, the influent wastewater samples were spiked at two different levels ( 20 and $50 \mathrm{ng} \mathrm{L}^{-1}, n=3$ ) and analyzed according to the proposed procedure. At first the sample was analyzed without spiking. This was done in order to evaluate the levels on parabens in the original sample and the results of the analysis are shown in Table 6.

Table 6. Analysis of parabens in real samples (concentration in $\mathrm{ng} \mathrm{L}^{-1}$ ) using in-syringe MSPE/ HPLC-DAD, $n=6$, degrees of freedom $=5$.

\begin{tabular}{ccccc}
\hline Samples & Methyl P & Ethyl P & Propyl & Butyl \\
\hline Influent 1 & $947 \pm 3$ & $168 \pm 2$ & $108 \pm 1$ & $<$ LOQ \\
Influent 2 & $889 \pm 2$ & $267 \pm 3$ & $1988 \pm 9$ & $133 \pm 3$ \\
Effluent 1 & $392 \pm 3$ & $22.4 \pm 0.9$ & $<$ LOQ & $<$ LOQ \\
Effluent 2 & $<$ LOQ & $<$ LOQ & $1396 \pm 5$ & $132 \pm 2$ \\
Tap water & $<$ LOQ & $<$ LOQ & $629 \pm 3$ & $<$ LOQ \\
\hline
\end{tabular}

Figure 4 present the chromatogram of unspiked effluent water and a spiked sample after both were preconcentrated using in-syringe MSPE.

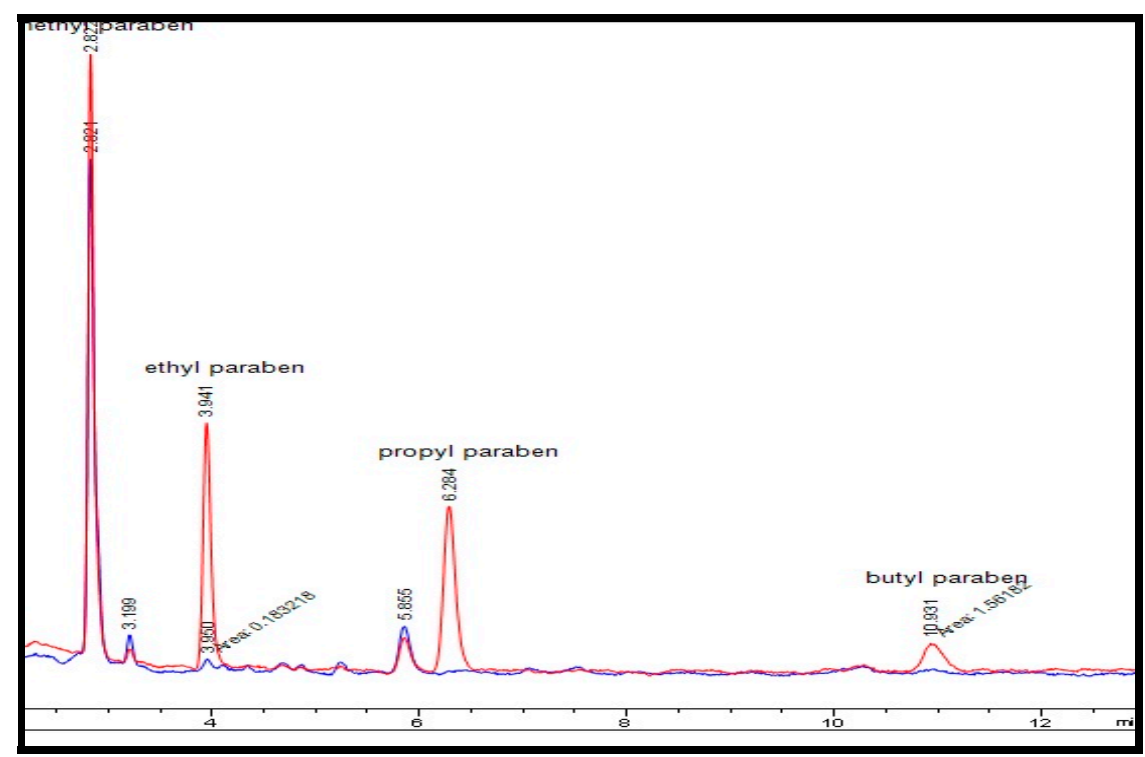

Figure 4. Chromatogram related to the extraction of target analytes (blue) wastewater (red) spiked wastewater at concentration level of $150 \mu \mathrm{g} \cdot \mathrm{L}^{-1}$ of analytes.

The percentage recoveries of paraben spiked at two levels were in the range of $97.5-99.4 \%$ with RSDs less than 5\% (Table 7). The results demonstrated that the developed method can effectively preconcentrate and sensitively detect of trace amount of parabens in the presence of sample matrices. 
Table 7. Validation of in-syringe MSPE for microextraction of parabens in spiked samples $(n=4)$

\begin{tabular}{|c|c|c|c|c|c|c|c|c|}
\hline \multirow{2}{*}{ Added $\left(\operatorname{ng~L~}^{-1}\right)$} & \multicolumn{2}{|c|}{ Methyl } & \multicolumn{2}{|c|}{ Ethyl } & \multicolumn{2}{|c|}{ Propyl } & \multicolumn{2}{|c|}{ Butyl } \\
\hline & Found $\left(\mathrm{ng} \mathrm{L}^{-1}\right)$ & \%Recovery & Found $\left(\operatorname{ng~L}^{-1}\right)$ & \%Recovery & Found (ng $\left.L^{-1}\right)$ & \%Recovery & Found (ng $\left.L^{-1}\right)$ & \%Recovery \\
\hline 0 & $392 \pm 3^{a}$ & - & $22.4 \pm 0.9$ & & ND & & ND & - \\
\hline 20 & $412 \pm 5$ & $98.0 \pm 1.2$ & $42.2 \pm 1.2$ & 99.0 & $19.5 \pm 0.5$ & $97.5 \pm 2.6$ & $19.6 \pm 0.4$ & $98.0 \pm 2.0$ \\
\hline 50 & $442 \pm 3$ & $99.5 \pm 0.8$ & 71.6 & 98.4 & $49.6 \pm 2.1$ & $99.2 \pm 4.2$ & $49.7 \pm 0.5$ & $99.4 \pm 4.0$ \\
\hline
\end{tabular}

a mean \pm standard deviation $(n=3)$. 
The in-syringe MSPE/HPLC-DAD method was successfully applied for preconcentration and determination of parabens in real samples and the analytical results are presented in Table 6 . The results obtained by the current method were not significantly different from those obtained by reference method. These results obtained indicated the applicability of the in-syringe MSPE/ HPLC-DAD method for determination of parabens in environmental water samples

\section{Material and Methods}

\subsection{Reagents and Standards}

Methyl-, ethyl-, propyl- and butyl parabens were purchased from Sigma-Aldrich (St. Loius, MO, USA). HPLC grade solvents, including methanol and acetonitrile, were from Sigma-Aldrich (St. Louis, $\mathrm{MO}, \mathrm{USA})$. Stock solutions of parabens $\left(10 \mathrm{mg} \mathrm{L}^{-1}\right)$ were prepared in ultra-pure water (Direct- $\mathrm{Q}^{\circledR}$ 3UV-R purifier system, Millipore, Merck, Germany) and stored in a freezer at $4{ }^{\circ} \mathrm{C}$. The working standards were prepared by subsequent dilution of stocks.

\subsection{Instrumentation}

Chromatographic analysis was carried out by an Agilent HPLC 1200 infinity series system, equipped with photodiode array detector (Agilent Technologies, Waldbronn Germany). The chromatograms were recorded at $250 \mathrm{~nm}$ and $260 \mathrm{~nm}$. An Agilent Zorbax Eclipse Plus C18 column $(3.5 \mu \mathrm{m} \times 150 \mathrm{~mm} \times 4.6 \mathrm{~mm})$ (Agilent, Newport, CA, USA) was operated at an oven temperature of $25{ }^{\circ} \mathrm{C}$. The mobile phase was a mixture of $30 \%$ water (Mobile phase $\mathrm{A}$ ) and $70 \%$ methanol (mobile phase $\mathrm{C}$ ). A flow rate of

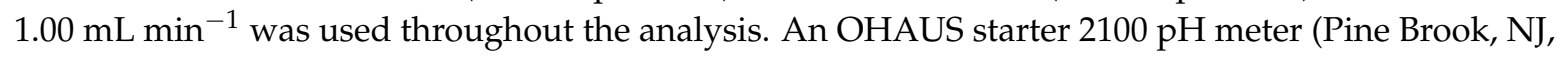
USA) was used for $\mathrm{pH}$ adjustments of the reagents and to measure the $\mathrm{pH}$ of samples.

The characterization of the adsorbents is crucial in their application for adsorption processes. The surface area $\left(\mathrm{S}_{\mathrm{BET}}\right)$ and pore size distribution of the adsorbent was determined from $\mathrm{N}_{2}$ adsorption-desorption isotherm using Brunauer, Emmett and Teller (BET) multipoint method using Surface Area and Porosity Analyzer (ASAP2020 V3. 00H, Micromeritics Instrument Corporation, Norcross, GA, USA). The pore volumes were calculated by the Barrerr-Joyner-Halenda method.

\subsection{Methods}

\subsubsection{Samples and Sample Collection}

Both raw (influent) and treated (effluent) wastewater samples were used in this study. Sewage wastewater samples were collected in different points in the Daspoort wastewater treatment plant (Pretoria, Gauteng, South Africa). The samples were collected in pre-cleaned $500 \mathrm{~mL}$ glass bottles. After sampling the water samples were stored at $4{ }^{\circ} \mathrm{C}$ for a maximum of 1 week until being analysed.

\subsubsection{Preparation of CAC Adsorbent and Self-Made in-Syringe MSPE Device}

Chitosan coated activated carbon adsorbent was synthesized according to the method described by Shariffard and colleagues [40]. Briefly, $5 \mathrm{~g}$ of activated carbon was treated with $0.2 \mathrm{~mol} \mathrm{~L}^{-1}$ oxalic acid for $4 \mathrm{~h}$. The activated carbon was then washed with deionised water after filtration and dried in an oven at $70{ }^{\circ} \mathrm{C}$ for $12 \mathrm{~h}$. After this, chitosan was also prepared by adding $5 \mathrm{~g}$ of chitosan to $500 \mathrm{~mL}$ in $0.2 \mathrm{~mol} \mathrm{~L}^{-1}$ oxalic acid solution under continuous stirring at $45-50{ }^{\circ} \mathrm{C}$ to form a viscous gel. Thereafter, the $5 \mathrm{~g}$ of the acid treated activated carbon was added slowly to the chitosan gel and stirred for $2 \mathrm{~h}$ at $45-50^{\circ} \mathrm{C}$. Then the activated carbon coated with chitosan beads were prepared by dropwise addition of the activated carbon gel into $0.7 \mathrm{M} \mathrm{NaOH}$ precipitation bath. The beads were filtered from $\mathrm{NaOH}$ bath and washed several times with deionised water to a neutral $\mathrm{pH}$ and dried in an air oven at $50{ }^{\circ} \mathrm{C}$. The in-syringe SPE device [33] was prepared through slurry-packing CAC powders in the syringe-cartridge of with upper and lower filters. To discuss the methodology in detail, $81 \mathrm{mg}$ CAC was added into $1 \mathrm{~mL}$ of deionized water and ultrasonicated to obtain a homogeneous dispersion. 
Afterwards, the dispersion was transferred to the barrel, and the plunger was pushed slowly to remove the deionized water from dispersion. During this process, CAC particles were gradually deposited on the surface of lower filter. The upper filter was subsequently embedded and compacted tightly to obtain a stable packing bed.

\subsubsection{In-Syringe SPE Procedure}

For pre-concentration of parabens in model and real water samples, the self-made in-syringe-SPE device was first preconditioned with $1 \mathrm{~mL}$ methanol and $1 \mathrm{~mL}$ deionized water, respectively. After the conditioning step, the synthetic sample solution $\left(100 \mu \mathrm{g} \mathrm{L}^{-1}\right)$ was passed through the device packed with adsorbent and then discharged from syringe cartridge though pushing the plunger. The estimated residence time of the sample solution in MSPE device was about $1 \mathrm{~min}$. Subsequently, the plunger was drawn-pushed for several times in the air to remove the residual water from the device. The adsorbent was washed with $1 \mathrm{~mL}$ \% methanol/water to remove the interferences. Finally, the parabens adsorbed on CAC were eluted with $800 \mu \mathrm{L}$ methanol by aspirating and dispensing the eluent for two cycles.

The eluate was injected into HPLC-DAD system for qualitative and quantitative analysis. After each extraction, the adsorbent was successively washed with $1 \mathrm{~mL}$ methanol and $1 \mathrm{~mL}$ water for the next extraction. The optimization of extraction and pre-concentration conditions was performed using experimental design approach based central composite design (CCD). The factors investigated included mass of adsorbent, $\mathrm{pH}$ of sample solution and eluent volume (Table 8). The statistical analysis was achieved using Statistica software (Version 13, StatSoft, Inc., Tulsa, OK, USA).

Table 8. Factors and levels of experimental design.

\begin{tabular}{cccc}
\hline Variables & Low Level (-1) & Centre Point (0) & High Level (+) \\
\hline Mass of Adsorbent $(\mathrm{mg})$ & 25 & 72 & 100 \\
Sample pH & 4.0 & 6.6 & 9.0 \\
Eluent Volume $(\mu \mathrm{L})$ & 200 & 720 & 1000 \\
\hline
\end{tabular}

\section{Conclusions}

The study proposed a method which allowed for the simultaneous determination of trace levels of four common parabens in wastewater. Its procedure was based on an in-syringe-SPME pre-concentration technique followed by HPLC-DAD analysis of the parabens. This method was successfully applied to the analysis of wastewater collected from the Daspoort wastewater treatment plant (WWTP, Pretoria, Gauteng, South Africa). Compared to other methods reported in the literature, this technique offers simplicity, ease of use, cost effectiveness and lower consumption of organic solvents. It could effectively detect the most commonly used parabens (methyl and propyl paraben) throughout the study as the concentration of methyl paraben remained constant and propyl paraben was detected in all three analytes. Thus the adsorbent CAC was highly effective in the pre-concentration procedure for the analyses of the parabens

Author Contributions: G.P.M., A.M. and P.N.N. formulated the research idea; P.N.N. and G.P.M. designed the experiments; G.P.M. performed the actual experiments and data collection; G.P.M. and A.M. carried out the analysis of data and A.M. provided instrumental training; G.P.M. wrote the first draft of the manuscript and P.N.N. review and edited the final version of the manuscript; G.P.M., A.M. and P.N.N. collected real water samples.

Funding: This research was funded by National Research Foundation; grant No. 99720

Acknowledgments: This study was supported by the University of Johannesburg, South Africa (Department of Applied Chemistry, Centre for Nanomaterial Science Research) and National Research Foundation, South Africa.

Conflicts of Interest: The authors declare no conflict of interest. 


\section{References}

1. Juliano, C.; Magrini, G.A. Cosmetic ingredients as emerging pollutants of environmental and health concern. A Mini-Review. Cosmetics 2017, 4, 11. [CrossRef]

2. Zhong, Z.; Li, G. Current trends in sample preparation for cosmetic analysis. J. Sep. Sci. 2017, 40, 152-169. [CrossRef] [PubMed]

3. Brausch, J.M.; Rand, G.M. A review of personal care products in the aquatic environment: Environmental concentrations and toxicity. Chemosphere 2011, 82, 1518-1532. [CrossRef] [PubMed]

4. Blanco, E.; del Carmen Casais, M.; del Carmen Mejuto, M.; Cela, R. Combination of off-line solid-phase extraction and on-column sample stacking for sensitive determination of parabens and p-hydroxybenzoic acid in waters by non-aqueous capillary electrophoresis. Anal. Chim. Acta 2009, 647, 104-111. [CrossRef] [PubMed]

5. Hashemi, B.; Shamsipur, M.; Fattahi, N. Solid-phase extraction followed by dispersive liquid-liquid microextraction based on solidification of floating organic drop for the determination of parabens. J. Chromatogr. Sci. 2015, 53, 1414-1419. [CrossRef] [PubMed]

6. Ocaña-González, J.A.; Ramos-Payán, M.; Fernández-Torres, R.; Navarro, M.V.; Bello-López, M.Á. Application of chemiluminescence in the analysis of wastewaters-A review. Talanta 2014, 122, 214-222. [CrossRef] [PubMed]

7. Darbre, P.D.; Harvey, P.W. Paraben esters: Review of recent studies of endocrine toxicity, absorption, esterase and human exposure, and discussion of potential human health risks. J. Appl. Toxicol. 2008, 28, 561-578. [CrossRef] [PubMed]

8. Harvey, P.W.; Darbre, P. Endocrine disrupters and human health: Could oestrogenic chemicals in body care cosmetics adversely affect breast cancer incidence in women. J. Appl. Toxicol. 2004, 24, 167-176. [CrossRef] [PubMed]

9. Albero, B.; Sánchez-Brunete, C.; Miguel, E.; Pérez, R.A.; Tadeo, J.L. Determination of selected organic contaminants in soil by pressurized liquid extraction and gas chromatography tandem mass spectrometry with in situ derivatization. J. Chromatogr. A 2012, 1248, 9-17. [CrossRef] [PubMed]

10. Terasaki, M.; Makino, M. Determination of chlorinated by-products of parabens in swimming pool water. Int. J. Environ. Anal. Chem. 2008, 88, 911-922. [CrossRef]

11. Villar-Navarro, M.; del Carmen Moreno-Carballo, M.; Fernández-Torres, R.; Callejón-Mochón, M.; Bello-López, M.Á. Electromembrane extraction for the determination of parabens in water samples. Anal. Bioanal. Chem. 2016, 408, 1615-1621. [CrossRef] [PubMed]

12. Lee, M.R.; Lin, C.Y.; Li, Z.G.; Tsai, T.F. Simultaneous analysis of antioxidants and preservatives in cosmetics by supercritical fluid extraction combined with liquid chromatography-mass spectrometry. J. Chromatogr. A 2006, 1120, 244-251. [CrossRef] [PubMed]

13. Núñez, L.; Tadeo, J.L.; García-Valcárcel, A.I.; Turiel, E. Determination of parabens in environmental solid samples by ultrasonic-assisted extraction and liquid chromatography with triple quadrupole mass spectrometry. J. Chromatogr. A 2008, 1214, 178-182. [CrossRef] [PubMed]

14. Ferreira, A.M.C.; Möder, M.; Laespada, M.E.F. GC-MS determination of parabens, triclosan and methyl triclosan in water by in situ derivatisation and stir-bar sorptive extraction. Anal. Bioanal. Chem. 2011, 399, 945-953. [CrossRef] [PubMed]

15. Saraji, M.; Mirmahdieh, S. Single-drop microextraction followed by in-syringe derivatization and GC-MS detection for the determination of parabens in water and cosmetic products. J. Sep. Sci. 2009, 32, 988-995. [CrossRef] [PubMed]

16. Levchyk, V.M.; Zui, M.F. Gas Chromatographic determination of parabens after derivatization and dispersive microextraction. Fr.-Ukr. J. Chem. 2015, 3, 72-79. [CrossRef]

17. Chen, C.W.; Hsu, W.C.; Lu, Y.C.; Weng, J.R.; Feng, C.H. Determination of parabens using two microextraction methods coupled with capillary liquid chromatography-UV detection. Food Chem. 2018, 241, 411-418. [CrossRef] [PubMed]

18. Xiu-Qin, L.; Chao, J.; Wei, Y.; Yun, L.; Min-Li, Y.; Xiao-Gang, C. UPLC-PDAD analysis for simultaneous determination of ten synthetic preservatives in foodstuff. Chromatographia 2008, 68, 57-63. [CrossRef] 
19. Geara-Matta, D.; Lorgeoux, C.; Rocher, V.; Chebbo, G.; Moilleron, R. Contamination of wastewater by endocrine disruptors in France: Analytical development for triclosan, triclocarban and parabens. Tech. Sci. Method 2011, 10, 17-24.

20. Márquez-Sillero, I.; Aguilera-Herrador, E.; Cárdenas, S.; Valcárcel, M. Determination of parabens in cosmetic products using multi-walled carbon nanotubes as solid phase extraction sorbent and corona-charged aerosol detection system. J. Chromatogr. A 2010, 1217, 1-6. [CrossRef] [PubMed]

21. Piao, C.; Chen, L.; Wang, Y. A review of the extraction and chromatographic determination methods for the analysis of parabens. J. Chromatogr. B 2014, 969, 139-148. [CrossRef] [PubMed]

22. Farajzadeh, M.A.; Djozan, D.; Bakhtiyari, R. Use of a capillary tube for collecting an extraction solvent lighter than water after dispersive liquid-liquid microextraction and its application in the determination of parabens in different samples by gas chromatography-Flame ionization detection. Talanta 2010, 81, 1360-1367. [CrossRef] [PubMed]

23. Huang, Y.; Peng, J.; Huang, X. One-pot preparation of magnetic carbon adsorbent derived from pomelo peel for magnetic solid-phase extraction of pollutants in environmental waters. J. Chromatogr. A 2018, 1546, 28-35. [CrossRef] [PubMed]

24. Jain, R.; Mudiam, M.K.R.; Chauhan, A.; Ch, R.; Murthy, R.C.; Khan, H.A. Simultaneous derivatisation and preconcentration of parabens in food and other matrices by isobutyl chloroformate and dispersive liquid-liquid microextraction followed by gas chromatographic analysis. Food Chem. 2013, 141, 436-443. [CrossRef] [PubMed]

25. Ramírez, N.; Borrull, F.; Marcé, R.M. Simultaneous determination of parabens and synthetic musks in water by stir-bar sorptive extraction and thermal desorption-gas chromatography-mass spectrometry. J. Sep. Sci. 2012, 35, 580-588. [CrossRef] [PubMed]

26. González-Mariño, I.; Quintana, J.B.; Rodríguez, I.; Schrader, S.; Moeder, M. Fully automated determination of parabens, triclosan and methyl triclosan in wastewater by microextraction by packed sorbents and gas chromatography-mass spectrometry. Anal. Chim. Acta 2011, 684, 59-66. [CrossRef] [PubMed]

27. Cabaleiro, N.; De La Calle, I.; Bendicho, C.; Lavilla, I. An overview of sample preparation for the determination of parabens in cosmetics. TrAC Trends Anal. Chem. 2014, 57, 34-46. [CrossRef]

28. Wen, Y.; Chen, L.; Li, J.; Liu, D.; Chen, L. Recent advances in solid-phase sorbents for sample preparation prior to chromatographic analysis. TRAC Trends Anal Chem. 2014, 59, 26-41. [CrossRef]

29. Farajzadeh, M.A.; Yadeghari, A.; Khoshmaram, L. Combination of dispersive solid phase extraction and dispersive liquid-liquid microextraction for extraction of some aryloxy pesticides prior to their determination by gas chromatography. Microchem. J. 2017, 131, 182-191. [CrossRef]

30. Sajid, M.; Basheer, C. Layered double hydroxides: Emerging sorbent materials for analytical extractions. TrAC Trends Anal. Chem. 2016, 75, 174-182. [CrossRef]

31. Rodríguez-González, N.; González-Castro, M.J.; Beceiro-González, E.; Muniategui-Lorenzo, S.; Prada-Rodríguez, D. Determination of triazine herbicides in seaweeds: Development of a sample preparation method based on matrix solid phase dispersion and solid phase extraction clean-up. Talanta 2014, 121, 194-198. [CrossRef] [PubMed]

32. Vázquez, P.P.; Mughari, A.R.; Galera, M.M. Application of solid-phase microextraction for determination of pyrethroids in groundwater using liquid chromatography with post-column photochemically induced fluorimetry derivatization and fluorescence detection. J. Chromatogr. A 2008, 1188, 61-68. [CrossRef] [PubMed]

33. Zhang, X.; Wang, P.; Han, Q.; Li, H.; Wang, T.; Ding, M. Metal-organic framework based in-syringe solid-phase extraction for the on-site sampling of polycyclic aromatic hydrocarbons from environmental water samples. J. Sep. Sci. 2018. [CrossRef] [PubMed]

34. Dimpe, K.M.; Mpupa, A.; Nomngongo, P.N. Microwave assisted solid phase extraction for separation preconcentration sulfamethoxazole in wastewater using tyre based activated carbon as solid phase material prior to spectrophotometric determination. Spectrochim. Acta Part A Mol. Biomol. Spectrosc. 2018, 188, 341-348. [CrossRef] [PubMed]

35. Sharififard, H.; Nabavinia, M.; Soleimani, M. Evaluation of adsorption efficiency of activated carbon/chitosan composite for removal of $\mathrm{Cr}$ (VI) and Cd (II) from single and bi-solute dilute solution. Adv. Environ. Technol. 2017, 2, 215-227. [CrossRef] 
36. Nomngongo, P.N.; Ngila, J.C.; Msagati, T.A.; Moodley, B. Chemometric optimization of hollow fiber-liquid phase microextraction for preconcentration of trace elements in diesel and gasoline prior to their ICP-OES determination. Microchem. J. 2014, 114, 141-147. [CrossRef]

37. Khodadoust, S.; Sadeghi, H.; Pebdani, A.A.; Mohammadi, J.; Salehi, A. Optimization of ultrasound-assisted extraction of colchicine compound from Colchicum haussknechtii by using response surface methodology. J. Saudi Soc. Agric. Sci. 2017, 16, 163-170. [CrossRef]

38. Ramos-Payan, M.; Maspoch, S.; Llobera, A. A simple and fast Double-Flow microfluidic device based liquid-phase microextraction (DF- $\mu \mathrm{LPME}$ ) for the determination of parabens in water samples. Talanta 2017, 165, 496-501. [CrossRef] [PubMed]

39. Luiz Oenning, A.; Lopes, D.; Neves Dias, A.; Merib, J.; Carasek, E. Evaluation of two membrane-based microextraction techniques for the determination of endocrine disruptors in aqueous samples by HPLC with diode array detection. J. Sep. Sci. 2017, 40, 4431-4438. [CrossRef] [PubMed]

40. Regueiro, J.; Becerril, E.; Garcia-Jares, C.; Llompart, M. Trace analysis of parabens, triclosan and related chlorophenols in water by headspace solid-phase microextraction with in situ derivatization and gas chromatography-tandem mass spectrometry. J. Chromatogr. A 2009, 1216, 4693-4702. [CrossRef] [PubMed]

41. Ebrahimpour, B.; Yamini, Y.; Esrafili, A. Emulsification liquid phase microextraction followed by on-line phase separation coupled to high performance liquid chromatography. Anal. Chim. Acta 2012, 751, 79-85. [CrossRef] [PubMed]

42. González-Mariño, I.; Quintana, J.B.; Rodríguez, I.; Cela, R. Simultaneous determination of parabens, triclosan and triclocarban in water by liquid chromatography/electrospray ionisation tandem mass spectrometry. Rapid Commun. Mass Spectrom. 2009, 23, 1756-1766. [CrossRef] [PubMed]

43. Feizi, N.; Yamini, Y.; Moradi, M.; Karimi, M.; Salamat, Q.; Amanzadeh, H. A new generation of nano-structured supramolecular solvents based on propanol/gemini surfactant for liquid phase microextraction. Anal. Chim. Acta 2017, 953, 1-9. [CrossRef] [PubMed]

44. Molins-Delgado, D.; Díaz-Cruz, M.S.; Barceló, D. Ecological risk assessment associated to the removal of endocrine-disrupting parabens and benzophenone-4 in wastewater treatment. J. Hazard. Mater. 2016, 310, 143-151. [CrossRef] [PubMed] 